\title{
The prion protein and New World primate phylogeny
}

\author{
Igor Schneider $^{1}$, Horacio Schneider ${ }^{2}$, Maria Paula Schneider ${ }^{1}$ and Artur Silva ${ }^{1}$ \\ ${ }^{1}$ Universidade Federal do Pará, Centro de Ciências Biológicas, Departamento de Genética, Laboratório de \\ Polimorfismo de DNA, 66075-900, Belém, Pará, Brazil. \\ ${ }^{2}$ Universidade Federal do Pará, Núcleo de Estudos Costeiros, Laboratório de Genética e Biologia \\ Molecular, Bragança, Pará, Brazil.
}

\begin{abstract}
The $\operatorname{PrP}^{C}$ prion protein contains 250 amino acids with some variation among species and is expressed in several cell types. $\operatorname{PrP}^{\mathrm{C}}$ is converted to $\operatorname{PrP}^{\mathrm{sc}}$ by a post-translational process in which it acquires amino acid sequences of three-dimensional conformation of $\beta$-sheets. Variations in the prion protein gene were observed among 16 genera of New World primates (Platyrrhini), and resulted in amino acid substitutions when compared with the human sequence. Seven substitutions not yet described in the literature were found: $W \rightarrow R$ at position 31 in Cebuella, $\mathrm{T} \rightarrow \mathrm{A}$ at position 95 in Cacajao and Chiropotes, $\mathrm{N} \rightarrow \mathrm{S}$ at position 100 in Brachyteles, $\mathrm{L} \rightarrow \mathrm{Q}$ at position 130 in Leontopithecus (in the sequence responsible for generating the $\beta$-sheet 1), D $\rightarrow E$ at position 144 in Lagothrix (in the sequence responsible for the $\alpha$-helix 1), D $\rightarrow G$ at position 147 in Saguinus (also located in the $\alpha$-helix 1 region), and $\mathrm{M} \rightarrow \mathrm{I}$ at position 232 in Alouatta. The phylogenetic trees generated by parsimony, neighbor-joining and Bayesian analyses strongly support the monophyletic status of the platyrrhines, but did not resolve relationships among families. However, the results do corroborate previous findings, which indicate that the three platyrrhine families radiated rapidly from an ancient split.
\end{abstract}

Key words: prion protein, New World monkeys, molecular phylogeny.

Received: November 20, 2003; Accepted: May 13, 2004.

\section{Introduction}

Prions are infectious pathogens responsible for a group of severe neurodegenerative diseases, composed almost exclusively of a modified protein $\left(\mathrm{PrP}^{\mathrm{Sc}}\right)$. According to Caughey et al. (1991) the normal cellular $\operatorname{PrP}\left(\operatorname{PrP}^{\mathrm{C}}\right)$ is converted to $\mathrm{PrP}^{\mathrm{Sc}}$ by means of a post-translational process in which the beta sheet content of the protein increases. Studies performed in transgenic mice suggest that $\mathrm{PrP}^{\mathrm{Sc}}$ acts as a template in which the PrPC is rearranged to form a new molecule $\operatorname{PrP}^{\mathrm{Sc}}$, through a process facilitated by the so-called X-protein (Prusiner, 1991, 1997, 1998). Cellular $\operatorname{PrP}$ is composed of approximately 250 amino acids, a number that varies among species (Billeter et al., 1997). According to Mastrangelo and Westaway (2001), the structure of this protein includes a globular $\mathrm{C}$-terminal domain comprising three $\alpha$-helices and two short $\beta$ strands preceded by a larger, unstructured $\mathrm{N}$-terminal region.

Transmission of prion diseases depends on the similarity between the abnormal form of PrP and PrPC. Trans-

Send correspondence to Horacio Schneider. Universidade Federal do Pará, Centro de Ciências Biológicas, Departamento de Genética, Laboratório de Polimorfismo de DNA, 66075-900 Belém, Pará, Brazil. E-mail: hschneider@uol.com.br. mission is facilitated if the donor and receptor belong to the same species, although abnormal PrP can overcome the species barrier if donor and receptor molecules are similar enough for the conversion process to occur (Gee, 1996). Schätzl et al. (1995) examined the species barrier among human and non-human primates, sequencing the open reading frame (ORF) of $35 \mathrm{PrP}^{\mathrm{C}}$ genes from apes and monkeys. The authors found amino acid similarities ranging from 92.9 to $99.6 \%$, and a very similar arrangement of the PrP genes in all primates. Seven to ten amino acid substitutions were found in seven New World primate species (Platyrrhini) in comparison with humans. Furthermore, the phylogenetic tree depicted in their study showed New and Old World monkeys as monophyletic clades supported by 99\% and $100 \%$ of Maximum Parsimony Analysis (MP) bootstrap values, respectively. In addition, the Hominidae and Cercopithecidae families were also well supported by MP bootstrap values of $100 \%$ and $99 \%$, respectively.

In relation to the New World primates, Schätzl et al. (1995) included two representatives of callitrichins (Callithrix and Saguinus), one of Atelidae (Ateles), one of Pithecidae (Callicebus) and the three most basal lineages Saimiri, Cebus and Aotus. In the present paper, we increase 
the number of taxa of New World primates, including members of all 16 extant genera in an attempt to assess the usefulness of prion protein gene for resolving phylogenetic relationships at the family level.

\section{Material and Methods}

DNA samples from sixteen platyrrhine genera (Chiropotes satanas, Callimico goeldii, Cebuella pygmaea, Leontopithecus rosalia, Alouatta belzebul, Aotus lemurinus, Callicebus moloch, Ateles paniscus, Saguinus bicolor, Cacajao calvus, Callithrix jacchus, Cebus apella, Saimiri sciureus, Pithecia irrorata, Brachyteles arachnoides and Lagothrix lagothricha) were obtained from the DNA bank of the Laboratory of DNA Polymorphism of the Federal University of Pará in Belém, Brazil. Also included in the phylogenetic analysis were previously published prion protein DNA sequences for the following species (obtained from the genebank): Cercopithecus aethiops (U08291), Cercopithecus dianae (U08292), Aotus trivirgatus (U08293), Papio hamadryas (U08294), Cebus apella (U08295), Pan troglodytes (U08296), Colobos guereza (U08297), Macaca fascicularis (U08298), Hylobates lar (U08299), Gorilla gorilla (U08300), Macaca fuscata (U08301), Presbytis francoisi (U08302), Mandrillus sphinx (U08303), Callithrix jacchus (U08304), Pongo pygmaeus (U08305), Macaca nemestrina (U08306), Macaca mulatta (U08307), Symphalangus syndactylus (U08308), Ateles geoffroyi (U08309), Saimiri sciureus (U08310), Macaca arctoides (U08311), Callicebus moloch (U08312) (Schätzl et al., 1995).

For each DNA sample, a 650 base pair fragment of the prion protein gene was amplified using the 5-TGGAGGATGGAATACTGGGG-3 (NWF) and 5'-AGGTGGGGAGGAGAAGAGAG-3' (NWR) primers designed by us based on the New World primates sequences deposited by Schätzl et al. (1995) in the GenBank under the Accession Numbers U08293, U08295, U08304, U08309, U08310 and U08312. These primers are located outside the Open Reading Frame.

PCR amplification was performed in $30 \mu \mathrm{L}$ of reaction mixture containing $5 \mu \mathrm{L}$ of $1.25 \mathrm{mM}$ dNTP, $3 \mu \mathrm{L}$ of buffer ( $10 \mathrm{X}$ conc.), $1.5 \mu \mathrm{L}$ of $25 \mathrm{mM} \mathrm{MgCl}_{2}, 0.5 \mu \mathrm{L}$ of each primer $(200 \mathrm{ng} / \mu \mathrm{L}), 2 \mu \mathrm{L}$ of total DNA $(200 \mathrm{ng} / \mu \mathrm{L})$, $0.5 \mu \mathrm{L}$ of $1 \mathrm{U} / \mu \mathrm{L}$ Taq DNA polymerase (AmershamPharmacia Biotech. Inc., Piscataway, NJ, USA) and $17 \mu \mathrm{L}$ of autoclaved double distilled water. Amplification was performed in a model 2400 thermocycler (Applied Biosystems, Foster City, CA, USA) with a cycling profile of $94{ }^{\circ} \mathrm{C}$ for $45 \mathrm{~s}$ followed by 28 cycles of $94{ }^{\circ} \mathrm{C}$ for $30 \mathrm{~s}$, $58{ }^{\circ} \mathrm{C}$ for $30 \mathrm{~s}, 72{ }^{\circ} \mathrm{C}$ for $50 \mathrm{~s}$ and $72{ }^{\circ} \mathrm{C}$ for $5 \mathrm{~min}$. Amplified products were separated by electrophoresis in low melting point $1 \%$ agarose gel, excised and subsequently eluted with the Qiaex II Kit (Qiagen Inc., USA). Cloned products were purified and submitted to a cycle-sequencing reaction using the fluorescent-labeled di-deoxy terminators supplied in the ALF Express II DNA analyzer (Amersham Biosciences, USA). Sequencing reactions were performed in a Perkin Elmer 2400 thermocycler in $10 \mu \mathrm{L}$ reaction mixture containing $2 \mu \mathrm{L}$ of DNA, $0.5 \mu \mathrm{L}(1 \mathrm{mM})$ of primer, $2 \mu \mathrm{L}$ of BigDye mix, $3 \mu \mathrm{L}$ of buffer $(200 \mathrm{mM}$ Tris $/ 5 \mathrm{mM}$ $\mathrm{MgCl} 2)$ and $2.5 \mu \mathrm{L}$ of autoclaved double distilled water, with a cycling profile of 25 cycles of $96^{\circ} \mathrm{C}$ for $30 \mathrm{~s}, 50^{\circ} \mathrm{C}$ for $15 \mathrm{~s}$ and $60{ }^{\circ} \mathrm{C}$ for $3 \mathrm{~min}$. Unincorporated di-deoxynucleotides were removed by isopropanol washing according to the method given in the ABI chemistry manual. The products were separated by electrophoresis $(3 \mathrm{~h}$ at $3000 \mathrm{~V}$ ) and sequences collected using the Alf Express II automated sequencer. Sequences were deposited in GenBank under accession numbers AY765378-AY765393.

\section{Phylogenetic analysis}

The New World primate prion protein genes sequenced in this study were aligned to homologous sequences obtained from the GenBank using the ClustalX program (Thompson et al., (1997) with default parameters and the data converted to FASTA and NEXUS formats. Minor modifications in the alignment were made using the BIOEDIT sequence editor (Hall, 1999). Nucleotide saturation was assessed by plotting transitions and transversions against K2P distances (Kimura, 1980) using the DAMBE program version 4.0.65 (Xia and Xie, 2001). The Modeltest program (Posada and Crandal, 1998) was used to select the model of evolutionary change that best fitted the data. Phylogenetic reconstructions were performed using Maximum Parsimony (MP), Maximum Likelihood (ML) and Neighbor Joining (NJ) methods in PAUP, version 4.0b10 program (Swofford, 2003) and Bayesian inference in MrBayes version 3.0 (Huelsenbeck and Ronquist, 2001). Maximum Parsimony trees were obtained by branch and bound searches with random stepwise addition followed by TBR swapping. All shared gaps were considered as single events and treated as a fifth base for MP analysis. Conversely, they were treated as missing values in the ML and NJ distances analyses (Neighbor Joining). The commands used in MrBayes were based on the evolutionary model chosen by Modeltest. To be sure that Bayesian analyses were converging to similar posterior probabilities, four independent runs were performed using random starting trees.

Synonymous and non-synonymous substitution rates were estimated using PHYLOWIN, version 2.0 (Galtier $e t$ al., 1966) and were used to reconstruct phylogenetic trees by the neighbor-joining approach with 1000 bootstrap pseudo-replicates. The confidence of branch nodes was assessed through bootstrap analysis in PAUP (1000 pseudoreplicates for MP and 500 for ML). Bremer Decay Indexes (Bremer, 1994) were also estimated for MP using SEPAL (Salisbury, 2000). 


\section{Results and Discussion}

The Prion protein gene was sequenced in all $16 \mathrm{New}$ World monkey genera and the sequences were aligned to additional sequences of platyrrhines, and those of the Cercopithecidae and Hominidae, retrieved from GenBank. Transitions and transversions were plotted as a function of p-distance and no saturation was observed. All platyrrhine sequences obtained from the GenBank were almost identical to those of the same taxa sequenced in the present study. The number of non-synonymous and synonymous substitutions between different species of the same genus ranged from 0 to 3 and 2 to 9 , respectively, with the two Callithrix sequences being the most divergent overall (two nonsynonymous and nine synonymous changes). Despite these differences, the topology of the resulting phylogenetic trees was unaffected.

\section{Structural analysis}

According to Schätzl et al. (1995) the genomic DNA organization of the PpP genes of non-human primates is similar to that of humans and basically conserved over all species studied to date. Figure 1 shows 219 amino acid alignments of 16 platyrrhine genera encompassing three families (Schneider et al., 2000). Our alignment starts at amino acid 29, corresponding to that of Schätzl et al. (1995: Figure 2). As can be seen, there are five octapeptide repeats (sequence PHGGGWGQ) between site 51 and site 91 (bold type) near the $\mathrm{N}$ terminus, which, according to various authors (Viles et al., 1999; Jackson et al., 2001), is a copper binding site. Subsequently, there is a small stop transfer

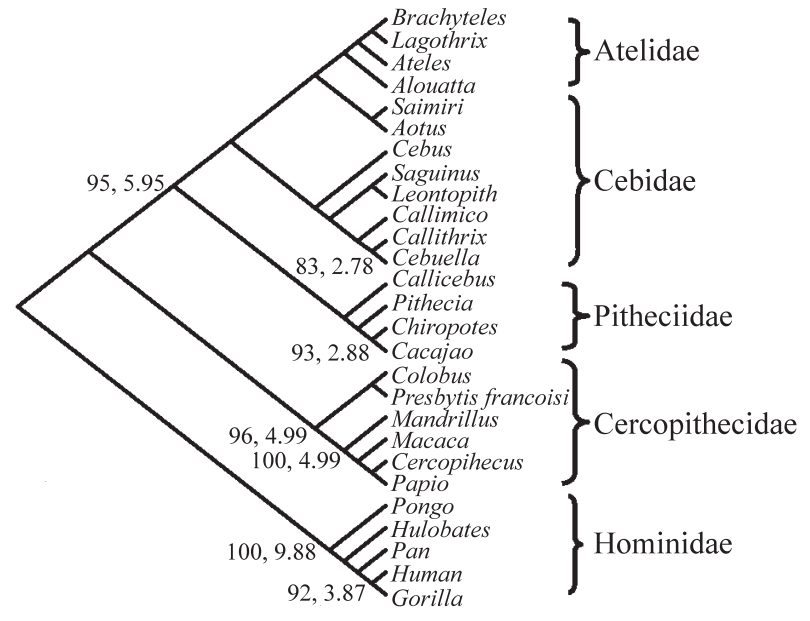

Figure 2 - Phylogenetic tree of New World primates using PrP genes. Numbers above branches means maximum parsimony bootstraps, decay index and Neighbor Joining bootstraps, respectively. Only significant bootstraps values are shown.

effector region (STE) and then from site 113 to 120, a highly conserved sequence motif (AGAAAAGA) inside the transmembrane region that is found in all PrPs, according to Mastrangelo and Westaway (2001).

In addition to the substitutions recorded by Schätzl et al. (1995), amino acid substitutions not yet described in the literature were found in nine platyrrhine species. The substitutions include $\mathrm{W} \rightarrow \mathrm{R}$ at position 31 (Cebuella), $\mathrm{G} \rightarrow \mathrm{S}$ at position 40 (Lagothrix), $\mathrm{T} \rightarrow \mathrm{A}$ at position 95 (Cacajao and Chiropotes), and $\mathrm{N} \rightarrow \mathrm{S}$ at position 100 (Brachyteles). Interestingly, Leontopithecus shows a L $\rightarrow$ Q substitution
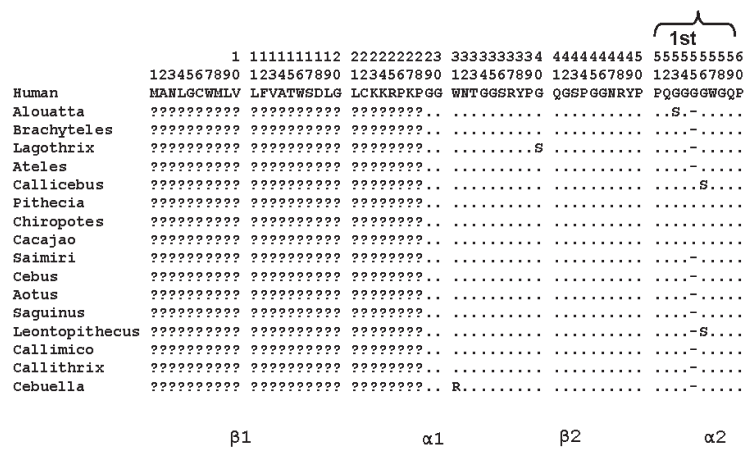

$1 1 1 1 1 1 1 1 1 1 1 1 1 1 1 1 1 1 1 1 1 1 \sqrt { 1 1 1 1 1 1 1 } 1 1 1 1 1 1 1 1 1 1 \longdiv { 1 1 1 1 } 1 1 1 1 1 1$ 1111111111 $\begin{array}{lllllll}2222222223 & 33333333334 & 4444444445 & 5555555556 & 6666666667 & 7777777778 \\ 1234567890 & 1334567890 & 1234567890 & 1234567890 & 1234567890 & 1234567890\end{array}$ VVGGLGGRIL GSAMSRPIIH FGSDYEDRYY REMHHRYPHQ VYYRPMDEYS WONHEYHDCV
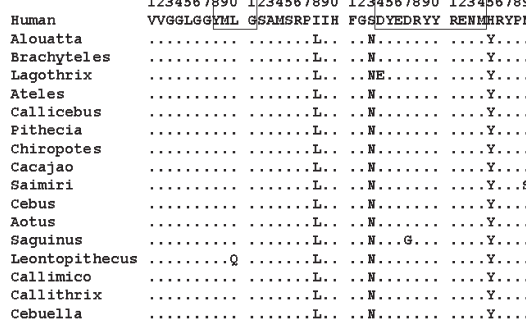

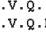

v. $\cdot$.

v.e.n

(n.

(n.

V.e.

.
v.Q.
v.

.V.Q.N

...v.Q.N

V.Q.N.N
V.Q.N
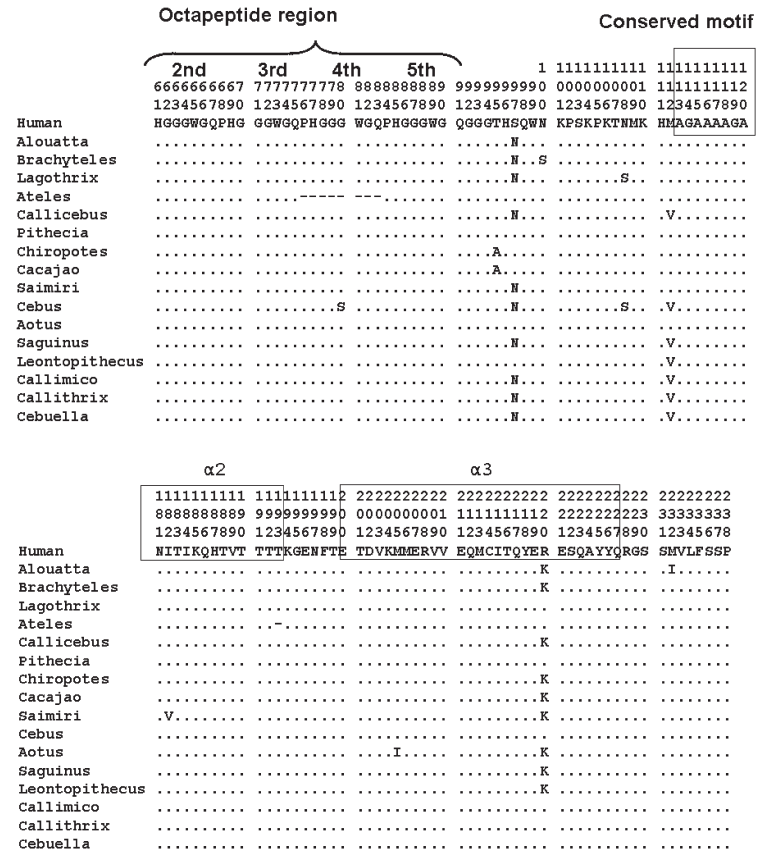

Figure 1 - Alignment of the 239 deduced amino acid sequences of PrPs. The non-human primate sequences were compared to the human PrP. Dots represent amino acids that are identical with human and question marks means missing data. Boxes represent alpha and beta helix domains. 
at position 130, located in the region responsible for assembling $\beta$-sheet 1 . Two other mutations were observed inside the $\alpha$-helix: $\mathrm{D} \rightarrow \mathrm{E}$ at position 144 in Lagothrix, and $\mathrm{D} \rightarrow \mathrm{G}$ at position 147 in Saguinus. Finally, Alouatta has an M $\rightarrow$ I substitution at position 232. The spider monkey (Ateles paniscus) sequenced in the present study does not exhibit the substitution $\mathrm{S} \rightarrow \mathrm{N}$ described by Schätzl et al. (1995) for Ateles geoffroyi.

This is interesting because Schätzl et al. (1995) found identical PrP sequences from codons 90 to 130 in three species highly susceptible to human prions, whereas in Ateles paniscus, we found a non-synonymous substitution $(\mathrm{S} \rightarrow \mathrm{N}: \mathrm{CAT} \rightarrow \mathrm{CAC})$ at position 97, different from Ateles geoffroyi, which shares a S amino acid with humans. This suggests that this region is not conserved in primates. Furthermore, Schätzl et al. (1995) found a substitution at codon $112(\mathrm{M} \rightarrow \mathrm{V})$ in marmosets (Callithrix) and capuchins (Cebus), which are thought to be poor hosts for the transmission of human prions. We found that this sub- stitution is also shared by all callitrichids, and Callicebus (Pitheciidae), in other words, it is present in all three platyrrhine families. Like spider monkeys, some lemurs also have MKHV instead of MKHM (http://www.madcow.org/00/jul00_late_sci.html). $\mathrm{M}$ and $\mathrm{V}$ may thus be found to be allelic in other primates, once enough species have been sequenced.

According to Schätzl et al. (1995) variations in the number of octarepeats are of considerable interest since the addition of two to nine octarepeats in humans results in inherited prion disease. These authors found an extra octarepeat localized between the third and fifth octarepeats in Saimiri sciureus (not shown in Figure 1), which was confirmed in the present study.

\section{Genetic distances}

Maximum likelihood genetic distances (Table 1) were estimated using the following parameters in the Lset command block in PAUP: Lset Base $=(0.24160 .2592$

Table 1 - Genetic distances estimated using likelihood settings from best-fit model (F81+G) selected by hierarchical likelihood ratio test (LRT) in Modeltest Version 3.06

\begin{tabular}{|c|c|c|c|c|c|c|c|c|c|c|c|c|c|c|c|c|c|c|c|c|c|c|c|c|c|c|}
\hline \multirow{2}{*}{$\frac{\text { Taxa }}{\text { Human }}$} & \multicolumn{26}{|c|}{ ML distances x 100} \\
\hline & & & & & & & & & & & & & & & & & & & & & & & & & & \\
\hline Gorilla & 0.3 & & & & & & & & & & & & & & & & & & & & & & & & & \\
\hline Pan & 0.7 & 0.3 & & & & & & & & & & & & & & & & & & & & & & & & \\
\hline Pongo & 2.5 & 2.1 & 2.5 & & & & & & & & & & & & & & & & & & & & & & & \\
\hline Hylobates & 2.7 & 2.3 & 2.3 & 3.1 & & & & & & & & & & & & & & & & & & & & & & \\
\hline Macaca & 6.3 & 5.7 & 5.7 & 5.2 & 7.6 & & & & & & & & & & & & & & & & & & & & & \\
\hline Cercopithecus & 6.1 & 5.5 & 5.5 & 4.7 & 7.5 & 0.0 & & & & & & & & & & & & & & & & & & & & \\
\hline Mandrillus & 6.7 & 6.1 & 6.1 & 5.8 & 8.0 & 0.3 & 0.3 & & & & & & & & & & & & & & & & & & & \\
\hline Colobus & 5.0 & 4.5 & 4.5 & 4.5 & 6.2 & 1.5 & 1.6 & 1.7 & & & & & & & & & & & & & & & & & & \\
\hline Papio & 6.6 & 6.0 & 6.0 & 5.5 & 7.9 & 0.2 & 0.2 & 0.5 & 1.7 & & & & & & & & & & & & & & & & & \\
\hline Presbytis & 5.0 & 4.5 & 4.5 & 4.5 & 6.2 & 1.5 & 1.6 & 1.7 & 0.6 & 1.7 & & & & & & & & & & & & & & & & \\
\hline Alouatta & 8.0 & 7.3 & 7.9 & 6.0 & 8.6 & 5.9 & 5.5 & 6.5 & 6.1 & 6.2 & 6.1 & & & & & & & & & & & & & & & \\
\hline Brachyteles & 7.3 & 6.7 & 6.7 & 5.0 & 7.9 & 4.4 & 4.4 & 5.0 & 5.1 & 4.7 & 5.1 & 2.5 & & & & & & & & & & & & & & \\
\hline Lagothrix & 7.1 & 6.5 & 7.1 & 4.8 & 7.7 & 5.2 & 5.2 & 5.8 & 5.4 & 5.4 & 5.9 & 3.1 & 1.2 & & & & & & & & & & & & & \\
\hline Ateles & 8.1 & 7.4 & 8.0 & 5.3 & 8.7 & 6.5 & 6.5 & 7.2 & 6.7 & 6.8 & 6.2 & 3.5 & 2.2 & 2.4 & & & & & & & & & & & & \\
\hline Callicebus & 7.3 & 6.7 & 6.7 & 5.4 & 8.1 & 4.9 & 4.6 & 5.2 & 5.5 & 5.1 & 5.5 & 3.7 & 2.4 & 3.5 & 4.6 & & & & & & & & & & & \\
\hline Pithecia & 6.0 & 5.4 & 5.4 & 4.2 & 6.7 & 4.6 & 4.6 & 4.9 & 3.9 & 4.9 & 3.9 & 3.9 & 2.7 & 3.3 & 3.7 & 2.3 & & & & & & & & & & \\
\hline Chiropotes & 6.8 & 6.2 & 6.2 & 5.2 & 7.9 & 5.2 & 5.2 & 5.5 & 4.4 & 5.4 & 4.4 & 4.4 & 3.1 & 4.2 & 4.6 & 2.7 & 1.3 & & & & & & & & & \\
\hline Cacajao & 6.2 & 5.7 & 5.7 & 4.7 & 7.3 & 4.6 & 4.6 & 4.9 & 3.9 & 4.9 & 3.9 & 3.9 & 2.6 & 3.7 & 4.1 & 2.2 & 1.0 & 0.3 & & & & & & & & \\
\hline Saimiri & 7.3 & 6.7 & 6.7 & 5.4 & 7.9 & 4.4 & 4.2 & 5.0 & 5.1 & 4.7 & 5.1 & 2.5 & 1.7 & 2.7 & 3.2 & 2.5 & 2.6 & 3.1 & 2.6 & & & & & & & \\
\hline Cebus & 7.9 & 7.2 & 7.2 & 6.4 & 7.9 & 4.9 & 4.6 & 5.2 & 5.1 & 5.1 & 5.1 & 3.7 & 2.5 & 2.7 & 3.7 & 2.8 & 2.6 & 3.5 & 3.0 & 2.5 & & & & & & \\
\hline Aotus & 7.8 & 7.1 & 7.1 & 5.8 & 8.4 & 5.2 & 4.7 & 5.8 & 5.4 & 5.5 & 5.4 & 2.9 & 2.3 & 3.3 & 3.2 & 3.1 & 2.9 & 3.3 & 2.9 & 1.9 & 2.7 & & & & & \\
\hline Saguinus & 7.1 & 6.5 & 6.5 & 5.7 & 7.6 & 5.1 & 4.9 & 5.4 & 4.9 & 5.4 & 5.3 & 3.1 & 1.9 & 2.5 & 3.4 & 2.3 & 2.8 & 3.3 & 2.8 & 1.9 & 2.3 & 2.5 & & & & \\
\hline Leontopithecus & 7.4 & 6.8 & 6.8 & 6.0 & 8.0 & 5.5 & 5.5 & 5.8 & 4.7 & 5.7 & 4.7 & 3.7 & 2.1 & 3.1 & 3.5 & 2.5 & 2.3 & 2.7 & 2.3 & 2.5 & 2.5 & 2.7 & 1.5 & & & \\
\hline Callimico & 6.8 & 6.2 & 6.2 & 5.0 & 7.3 & 5.9 & 5.6 & 6.2 & 5.6 & 6.1 & 5.1 & 3.7 & 2.1 & 2.7 & 2.4 & 2.8 & 2.6 & 3.5 & 3.0 & 2.5 & 2.4 & 3.1 & 1.5 & 1.7 & & \\
\hline Callithrix & 7.7 & 7.0 & 7.1 & 5.8 & 7.2 & 5.7 & 5.7 & 6.0 & 4.9 & 5.9 & 4.9 & 3.5 & 1.9 & 2.5 & 3.3 & 3.1 & 2.5 & 3.3 & 2.9 & 2.7 & 1.9 & 3.3 & 1.7 & 1.5 & 1.2 & \\
\hline Cebuella & 8.1 & 7.4 & 7.4 & 6.1 & 8.1 & 6.3 & 6.3 & 6.6 & 5.2 & 6.5 & 5.4 & 4.0 & 2.3 & 2.7 & 3.7 & 3.5 & 2.9 & 3.8 & 3.3 & 3.1 & 2.7 & 3.8 & 1.9 & 1.9 & 1.5 & 0.7 \\
\hline
\end{tabular}


0.3271 $)$ Nst $=6$ Rmat $=\left(\begin{array}{ll}1.0000 & 13.11991 .00001 .0000\end{array}\right.$ 19.8709) Rates $=$ gamma Shape $=0.8240$ Pinvar $=0.5976$. In the Hominidae, values varied from $0.3 \%$ among humans, chimps and gorillas to $3.1 \%$ between orangutans and gibbons. As pointed out by Schätzl et al. (1995), gibbons appear to be more closely related to humans than orangutans. However, in our dataset using ML distances they are equally similar to humans. On the other hand, gibbons and humans are more similar in terms of non-synonymous sites, whereas orangutans and humans are more similar on the basis of synonymous sites (see Table 2). The reasons for this pattern may have been identified by Herbert and Easteal (1996). They detected a faster rate of substitution in the human lineage at the non-synonymous site of the protein prion gene in a comparative study of sixteen genomically dispersed genes, and suggested that this difference could be due to either directional selection or a reduction of functional constraints in the human lineage.

Among Old World primates, divergence values ranged from $0 \%$ between Macaca and Cercopithecus to 1.7\% (Colobus, Papio, Presbytes). On the other hand, among New World monkeys they varied from $0.3 \%$ between Cacajao and Chiropotes to $4.6 \%$ between Ateles and Callicebus. The mean genetic distance between humans and Old World monkey species was 6.0\% (range 5.0-6.7\%), whereas between humans and New World monkeys, it was $7.3 \%$ (range $6.0-8.1 \%$ ). This difference is expected according to the phylogenetic relatedness of catarrhines and platyrrhines, but contradict Schätzl et al. (1995), who asserted that PrP genes violate this expectation.

\section{The Evolutionary Model and Phylogenetic Reconstruction}

A total of 588 equally most parsimonious trees 165 steps in length were recovered. The MP analysis revealed 550 constant and 107 variable sites, 47 of which are parsimony-uninformative, and 60 informative. The consistence and re-scaled indexes were 0.693 and 0.589 , respectively.
The strict consensus tree exhibited the same topology presented by the bootstrap 50\% majority rule consensus tree (Figure 2).

Maximum parsimony and Neighbor Joining bootstrap analyses depict the same phylogenetic tree. Phylogenetic reconstruction was not able to resolve intra- or inter-familial relationships in New World monkeys, presenting an unresolved polytomic arrangement. Even Callithrix-Cebuella clade, which is strongly supported (more than 95\%) in various phylogenetic studies (Schneider et al., 1993; Schneider, 2000), are poorly supported here. However, the monophyletic status of the New World monkeys is strongly supported by significant bootstrap values $(\mathrm{BS}=95 \%)$ and decay indexes $(\mathrm{DI}=5)$. This is due primarily to variation in the third base in synonymous substitutions typical of highly conserved genes. When phylogenetic reconstruction was conducted excluding the third base or considering only non-synonymous changes, the monophyletic status of the platyrrhine is no longer supported (data not shown). On the other hand, in the Old World, both Cercopithecidae and Hominidae are supported significantly by bootstrap values ranging from 96 to $100 \%$ and decay indexes of four to nine. As emphasized by Schätzl et al. (1995), the PrP gene clusters the Hominina (Homo, Pan and Gorilla) first with Hylobates rather than Pongo (BS = 95\%), contradicting the classic division (Groves, 1997; Miyamoto et al., 1998; Goodman et al., 1989) of the Hominoidea into Hylobatidae (gibbons) and Hominidae (Ponginae and Homininae). This arrangement, while not strongly supported by bootstrap analyses, was also found in the epsilon gene in platyrrhines by Schneider et al. (1993). However, Chen et al. (2003) recommend the analysis of a large number of data sets, so the apparent similarity of gibbons to humans should be treated with caution.

Bayesian analysis revealed a topology similar to MP and NJ trees, differing, in relation to the high credibility values, which were $100 \%$ for all nodes with MP bootstrap values higher than $80 \%$ and for grouping, regardless of significance, tamarins and marmosets (including Callimico)

Table 2 - Estimation of non synonymous and synonymous rate by the method of Yang \& Nielsen (2000).

\begin{tabular}{llcc}
\hline Taxa & & Non synonymous distance & Synonymous distance \\
\hline Gorilla & Human & $0.0023 \pm 0.0023$ & $0.0064 \pm 0.0064$ \\
Chimpanzee & Human & $0.0045 \pm 0.0032$ & $0.013 \pm 0.0092$ \\
Chimpanzee & Gorilla & $0.0023 \pm 0.0023$ & $0.0064 \pm 0.0064$ \\
Orang otan & Human & $0.0091 \pm 0.0046$ & $0.0592 \pm 0.0201$ \\
Orang otan & Gorilla & $0.0068 \pm 0.004$ & $0.0521 \pm 0.0187$ \\
Orang otan & Chimpanzee & $0.0091 \pm 0.0046$ & $0.0592 \pm 0.0201$ \\
Gibbon & Human & $0.0045 \pm 0.0032$ & $0.0814 \pm 0.0242$ \\
Gibbon & Gorilla & $0.0023 \pm 0.0023$ & $0.0739 \pm 0.0228$ \\
Gibbon & Chimpanzee & $0.0000 \pm 0.0000$ & $0.0814 \pm 0.0241$ \\
Gibbon & Orang otan & $0.0092 \pm 0.0046$ & $0.0723 \pm 0.0223$ \\
\hline
\end{tabular}


with $86 \%$ of creditibility (not shown), and also for grouping together all members of Pithecidae (Pithecia, Cacajao, Chiropotes and Callicebus; sensu Schneider, 2000) in spite of the low credibility value of $54 \%$ (not shown).

The fact that the prion protein gene can be used to resolve the branching pattern of catarrhine families, but not platyrrhines, corroborates previous results (Schneider et al., 2000; Goodman et al., 1998) which indicate that platyrrhine families are ancient lineages that originated over a short period of time, and then radiated rapidly.

\section{References}

Billeter M, Riek R, Wider G, Hornemann S, Glockshuber R and Wüthrich K (1997) Prion protein NMR structure and species barrier for prion diseases. Proc Natl Acad Sci USA 94:7281-7285.

Bremer K (1994) Branch support and tree stability. Cladistics 10:295-304.

Caughey B and Raymond GJ (1991) The scrapie-associated form of $\operatorname{PrP}$ is made from a cell surface precursor that is both protease- and phospho-lipase-sensitive. J Biol Chem 266:18217-18223.

Chen WJ, Bonillo C and Leointre G (2003) Repeatibility of clades as a criterion of reliability: A case study for molecular phylogeny of Acanthomorpha (Teleostei) with larger number of taxa. Mol Phyl Evol 26:262-288.

Galtier N, Gouy M and Gautier C (1996). SEAVIEW and PHYLO_WIN: Two graphic tools for sequence alignment and molecular phylogeny. CABIOS 12:543-548.

Gee H (1996) Molecular Evolution of Prions [on line]. Nature, 1996. http://www.mad-cow.org/ tom/prion_evol.html.

Goodman M, Koop BF, Czelusniak J, Fitch DH, Tagle DA and Slightom JL (1989) Molecular phylogeny of the family of apes and humans. Genome 31:316-35.

Groves CP (1997) Taxonomy and phylogeny of primates. In: Blancher A, Klein J and Socha WW (eds) Molecular Biology and Evolution of Blood Group and MHC Antigens in Primates. Springer-Verlag, Berlin.

Hall TA (1999) BioEdit: A user-friendly biological sequence alignment editor and analysis program for Windows 95/98/NT. Nucleic Acids Symposium Series 41:95-98.

Herbert G and Easteal S (1996) Relative rates of nuclear DNA evolution in human and Old World monkey lineages. Mol Biol Evol 13:1054-1057

Huelsenbeck JP and Ronquist F (2001) MrBayes: Bayesian inference of phylogenetic trees. Bioinformatics 17:754-755.
Jackson GS, Murray I, Hosszu L, Gibbs N, Waltho JP, Clarke AR and Collinge J (2001) Location and properties of metal-binding sites on the human prion protein. Proc Natl Acad Sci USA 98:8531-8535.

Kimura M (1980) A simple method for estimating evolutionary rate of base substitutions through comparative studies of nucleotide sequences. J Mol Evol 16:111-120.

Mastrangelo P and Westaway D (2001) Biology of the prion gene complex. Biochem Cell Biol 79:613-28.

Miyamoto MM, Koop BF, Slightom JL, Goodman M and Tennant MR (1988) Molecular systematics of higher primates: Genealogical relations and classification. Proc Natl Acad Sci USA 85:7627-31

Posada D and Crandall KA 1998 MODELTEST: Testing the model of DNA substitution. Bioinformatics 14:817-818.

Prusiner SB (1991) Molecular biology of prion diseases. Science 252:1515-1522

Prusiner SB (1997) Prion diseases and the BSE crisis. Science 278:245-251.

Prusiner SB (1998) Prions. Proc Natl Acad Sci USA 95:1336313383.

Salisbury BA (2000) Strongest evidence revisited. Cladistics 16:394-402.

Schätzl HM, da Costa M, Taylor L, Cohen FE and Prusiner SB (1995) Prion protein gene variation among primates. J Mol Biol 245:362-374.

Schneider H (2000) The current status of the molecular phylogeny of New World monkeys. An Acad Bras Ci 72:165-172.

Schneider H, Schneider MPC, Sampaio I, Harada ML, Stanhope M, Czelusniak J and Goodman M (1993) Molecular phylogeny of New World monkeys (Platyrrhini, Primates). Mol Phyl Evol 22:225-242.

Swofford DL (2003) PAUP* Phylogenetic Analysis Using Parsimony (*and Other Methods). Version 4. Sinauer Associates, Sunderland, Massachusetts.

Thompson JD, Gibson TJ, Plewniak F, Jeanmougin F and Higgins DG (1997) The Clustal_X windows interface: Flexible strategies for multiple sequence alignment aided by quality analysis tools. Nucleic Acids Research 25:4876-4882.

Viles JH, Cohen FE, Prusiner SB, Goodin D, Wright PE and Dyson HJ (1999) Copper binding to the prion protein: Structural implications of four identical cooperative binding sites. Proc Natl Acad Sc USA 96:2042-2047

Xia X and Xie Z (2001) DAMBE: Data analysis in molecular biology and evolution. J Hered 92:371-373.

Yang Z and Nielsen R (2000) Estimating synonymous and nonsynonymous substitution rates under realistic evolutionary models. Mol Biol Evol 17:32-43.

Associate Editor: Sergio Furtado dos Reis 